for a severely limited and practical book of tables. The actual demand for these turned out to be so disappointing that their publication had to cease.

No doubt it would be very neat, tidy, and regimental if all navigators in all types of ships somehow or another reached agreement that they would in future all use precisely the same tables, the same almanac, and the same methods and techniques; but one feels that it will be a very long time before this comes to pass. I, for one, have no regrets that I shall not live to see the day. Variety is the spice of life.

\title{
The Accuracy of Dead Reckoning in the Air
}

\author{
from Captain E. D. Maya \\ (Transportes Aéreos Portugueses)
}

1. Introduction. We have followed what has been written in this Journal about the accuracy of dead reckoning in the air and the determination and use of the most probable position. We wish to refer in particular to the article by J. B. Parker entitled 'The navigational implications of Mr. Durst's paper' (this Journal, 8, I I 3 ). We are not familiar with the routes of the North Atlantic or Central Africa; we have, however, eight years experience on the routes LisbonLuanda-Lourenço Marques, via Dakar, as well as those overflying the Sahara Desert via Oujda and via Agadir. The following considerations are in great part the result of that experience.

2. Accuracy OF DEAD RECKONING. It seems to us extremely difficult to apply in practice the statistical concept of a D.R. error with the object of its application to the routine work of navigation in flight and thereby contribute to the safety of the operation.

Taking now into account only the error due to the forecast meteorological wind, the assertion can be made at once that the linear error in the D.R. position per hour is not greater than the sum of the strength of the max. wind existing in the area, with the strength of the wind used to calculate the course to steer. This observation, though self-evident, appears to us to have a somewhat deeper meaning than would appear at first sight.

Our experience, using $\mathrm{DC}_{3}, \mathrm{DC}_{4}$ and Super Constellation aircraft on the aforementioned routes, especially on those overflying the Sahara Desert, shows us that there are regions where the winds are definitely more constant, not very strong, and more in accordance with those foreseen by the Met. services; and others where a surprise is always to be expected, as the winds are there more irregular, generally stronger, and sometimes much more at variance with those that had been forecast.

To increase the preoccupations of the navigator and the captain of the aircraft, precisely in the regions where these last conditions occur, terrain clearance problems exist to such an extent that safety of the flight may be impaired should the route be flown by aircraft with no pressurized cabin. As we think that this subject is an interesting one, we proceed to discuss each one of those regions. 
(a) Regions of big discrepancies between forecast and found winds

i. Region South-east of Agadir. This region is influenced by the sub-tropical jet stream, the structure of which is in general incorrectly defined due to lack of meteorological elements. Thus, at the level of $500 \mathrm{mb}$., westerly winds stronger than those forecast are occasionally encountered, giving rise to great errors, sometimes of the order of $60 \mathrm{n.m}$. in a one-hour flight, in D.R. position. Such winds, being due to a jet stream, are felt in relatively narrow bands, making it difficult for the navigator to notice their existence when not forecast by the Met. Considerable errors in D.R. position have also been found at the level of $700 \mathrm{mb}$. If it is true that the winds at this level, when influenced by the above mentioned jet stream, should logically be weaker than at $500 \mathrm{mb}$., the fact is that the local ground conditions, among them the existence of the Atlas mountains, and the lack of meteorological information in the region, make wind forecasting quite difficult.

ii. Region South of Oujda. The meteorological forecast in this region presents great difficulties, because of lack of information as well as on account of the nature of the ground, which is very uneven.

At the level of $700 \mathrm{mb}$. we have experienced cases where, instead of moderate westerly winds, moderate easterly winds were encountered, giving rise to offcourse deviations of the order of 40 to $50 \mathrm{n} . \mathrm{m}$. in a one-hour flight. Deviations of the order of $20 \mathrm{n} . \mathrm{m}$. per hour are more frequent, due mainly to westerly winds stronger than those forecast. At $500 \mathrm{mb}$. we have experienced deviations of the order of 50 miles, which were generally due to westerly winds stronger than those forecast.

iii. Region between Livingstone and Lourenço Marques. Due to strong headwind components which had not been forecast, some of our Super Constellations have arrived at Livingstone with a delay of about 45 minutes in relation to time estimated in the flight plan (on a route of approximately three hours flight). Very recently, our actual position, confirmed by two 3 -star fixes, was $60 \mathrm{n} . \mathrm{m}$. abeam of the D.R. position, $1 \frac{1}{2}$ hours after take-off from Lourenço. Marques. However, this is not an exceptional case. We think that, in this region, the question is not that the winds are very much stronger than those forecast, but that they blow in directions other than those forecast.

Summarizing, we have shown typical examples of large errors in D.R. positions which are chiefly due to discrepancies between forecast and found wind. As a result we can assert that there is no navigator on these routes who is not mentally prepared for deviations of the order of 60 n.m. within 1 hour flight in relation to the D.R. position, in any of the three indicated regions.

\section{(b) Regions of agreement between forecast and found winds}

On the other hand, there are other regions where winds are more regular and forecasts are generally good in spite of the lack of data with which the meteorological services of those regions are confronted. We refer, for example, to the regions between $\mathrm{S}$. Tomé and Luanda ( 500 and $700 \mathrm{mb}$.), and between Dakar and Accra $(700 \mathrm{mb}$.), where it is very unusual for the navigator to meet winds markedly different from those forecast by Met. Also, as the winds are not strong, the error in D.R. is never very great; accordingly, from the navigational viewpoint, no problems are created to affect the safety of flight.

3. The use of The D.R. Position. A D.R. position, being the estimated 
position of the aircraft calculated from the data available from the last fix (therefore based on TAS., course steered, and estimated wind), is mainly used for:

(a) traffic separation;

(b) position reports and estimation of times of arrival;

(c) course alterations;

(d) safety of flight in relation to ground;

(e) determination of the M.P.P.;

(f) astro fix calculations;

(g) pre-selecting Consol azimuths, \&c.

Logically, the captain and the navigator wish to give a D.R. position a determined area of uncertainty which will permit them, if the worst comes to the worst, to ensure that the decisions which are taken with that D.R. position as a basis do not affect the safety of flight. Of course, the problem of the uncertainty of the D.R. has little practical interest when there are no safety problems, and it is fundamental when safety may be affected. In the first case, the actual position of the aircraft is taken as the D.R. position; in the second case, fairly great errors will have to be catered for in accordance with the region overflown, the period, the density and reliability of the Met. information, and the navigator's experience.

4. THE D.R. POSITION ERROR. We are not sure that the error in the D.R. position can always be adequately represented by a circle containing a given percentage of the true positions. We think that, for some special routes, we may better specify the error by four parameters:

(a) The percentage error along the track in one direction from the D.R. position.

(b) The percentage error along the track in the opposite direction (in relation to $(a)$ ) from the D.R. position.*

(c) The percentage error abeam of the track in one direction.

(d) The percentage error abeam of the track in the opposite direction (in relation to $(c))$.

Such will be necessary whenever the winds blow predominantly in a given direction, or big discrepancies occur always for a given direction. For example, in the Agadir region, one can reasonably expect an 8o-knot unforeseen westerly wind, but assuredly will not be prepared for a high-speed easterly wind.

It seems to us, therefore, that the statistical study of the D.R. position error is a very interesting one, but that:

(a) Such a study should be particularly made for route segments having similar characteristics;

(b) The error to be considered should not be the probable error, but the 95 per cent error;

(c) As Mr. Parker has pointed out, the error should be referred to specified flight levels, to the winds as forecast by Met., to the particular period of the year, and for a given speed range of the aircraft;

* Note: We don't use the words 'forward', 'backward', 'starboard', and 'port', as this depends on the direction in which we fly the route. 
(d) The error should be defined by the radius of the circle containing so many per cent of the true positions, or by the values of the errors across or along the track from the D.R. position ( 2 or 4 values, as required), depending on the characteristics of the occurrence of unpredicted winds on the area.

We should bear in mind, however, that, if we admit the probability level of 95 per cent (as we suggest), there will be occasionally ( 5 per cent of cases) greater errors than those considered. It is therefore necessary, as we have said, to keep in mind that the greatest possible error in each case is equal to the sum of the strength of the strongest wind existing in the region, with the strength of the wind used to calculate the course to steer, plus the errors derived from compass and airspeed improper calibration, and incorrect steering. If statistical studies are to be made on the subject, the results obtained could be included, for use of crews, in the appropriate route manuals.

5. Answers to Mr. Parker's Questions. We shall finally try to answer the questions raised by Mr. Parker in his article, and, in doing so, we must refer ourselves basically to the drills we are using in our routine navigation work.

(1) Track Keeping to Within Definite Limits: It is difficult, in civil aviation, when using mainly astro navigation, to obtain fixes at a rate higher than one per hour. Sometimes, due to weather conditions, we must fly much more than one hour without obtaining a fix, or even a single position line. Keeping this in mind, we must readjust the limits within which the track can be maintained in practice rather than the rate of fixing which seldom can be entirely controlled. Even using radio or radar navigation, we believe that the problems must be approached from the viewpoint we have expressed: the limits of track keeping should certainly be defined as a function of:

(a) precision of the definition of track, as permitted by the appropriate facilities;

(b) fixing rate available;

(c) precision of the fixes;

(d) precision of the D.R. positions between fixes.

(2) Search and Rescue. No comment.

(3) Safety Altitudes. We believe that a band is a satisfactory way to base the calculations of safety altitudes. Such a band should by no means be uniform, but it should rather be defined taking the following into account:

(a) the 'positive' rate of fixing position (by 'positive' rate we mean the rate that is always available in practice);

(b) the maximum absolute error of the D.R. position between fixes, characteristic for the region;

(c) the general weather conditions en-route, as far as such weather conditions may imply changes of track to avoid bad weather;

(d) the crew training level and the navigation drills in use.

In addition to the above, we believe that the navigator must have a quick and efficient means of evaluating his actual safety altitude in case he is deviated from his normal track. To the best of my knowledge the general routine is to have the highest spot altitude for each 5 -degree quadricule marked on the plotting chart. We suggest that in regions where there is high ground to such an 
extent that the safety of flight may be affected, at least the spot height for each I-degree quadricule should be available. As an example of the application of these ideas, our Company has already specified safety bands with a total width ranging between 40 and 200 n.m., the latter being in force on our African routes. We have also available in the African Route Books the safety altitude within a band of $300 \mathrm{n} . \mathrm{m}$. We can give another example of variation from the standard band used in Europe: we do not approach Lugo Consol in IFR weather conditions or by night at an altitude below $10,000 \mathrm{feet}$, the standard safety altitude being 8000 feet. This is due to abnormal errors of the position lines from Lugo, when being used as a radio beacon.

All these values, although somewhat arbitrary, are fairly representative of the problems involving track keeping within limits and the related safety altitudes.

(4) Finding the Island. We think that homing down a position line can be a useful method when radio is not available. If we pre-compute and graphically display altitudes versus time of the celestial body to be used, as observed from the Island, one will see instantly after each sight how many miles one has still to fly before turning to the azimuth of the position line passing through the destination. This procedure can be used to the extent that practically no D.R. is necessary except to determine the E.T.A. at the Island, which is not critical. However, if we wish to transfer the position line that has been obtained a long time before, one should be prepared to search for the Island after the E.T.A. has passed.

(5) Most Probable Position. In practice, we do not calculate the M.P.P. when we obtain a fix either by stars or by radio. Although we do not have much confidence in radio fixes obtained from distant beacons, we either accept or disregard them, according to our former experience. However, in any case, the position found should be compared with the D.R. position; using mainly good practical sense and experience, one has to decide whether it should be accepted, or suspected of containing a mistake or an abnormal error.

In those cases where it is not possible to obtain more than one position line, it seems to us that we have a good justification to work out a M.P.P. Except in very special cases, we should not start a plot from such a M.P.P.; we think it is better to maintain it as started from the last fix. We also think that the drills to work out the M.P.P. 'should be revised.

We believe that we have found in Mr. Durst's paper (this Journal, 8, i 13 ) a clear reason for not calculating the M.P.P. in the case of a fix, this being that the standard deviation of the D.R. error per hour is, in general, much higher than the standard deviation of a two- or three-position line fix error. (We refer to a fixing rate of one fix per hour.)

(6) Fixing rates. We think this point has been already covered.

(7) Wind Utilization. In our work routine, we always compare the found wind with the forecast wind. Whenever these winds differ from each other, we refer to the contour chart hear the actual flight level and try to deduce which are the changes in the pressure system that would logically explain the found wind. The wind we use for the next hour depends therefore on the conclusions drawn from that analysis as well as, obviously, on the navigator's experience. Only very seldom do we use for the next hour the past found wind or the forecast wind, unless the analysis of the situation indicates that this is a reasonable solution. We can perhaps state as a rule that in all flights carrying a navigator crew 
member, the wind to be used for the next hour or leg is always an estimated wind based on the Met. upper level forecast charts, on forecast winds, and on previously found winds.

6. THEORY AND PRACTICE. We are dealing with a matter that affects safety. Therefore we are perhaps justified in finishing this work quoting the words of Air Chief Marshal the Hon. Sir Ralph Cochrane, at the end of the Ordinary Meeting of the Institute in December 1954:

For a good many years I had to read Courts of Inquiry into fatal accidents, and, as a result, I am afraid that I gained a profound mistrust of averages and standard errors. I know many of you have derived great value from them, but, as Mr. Parker said, if you draw your circle of uncertainty, or whatever you call it, you have only a fifty-fifty chance of being inside it. The reports to which I have just referred were on people who happened to be well outside it. I remember the last time I flew the Atlantic in a service aeroplane; we took off from Goose Bay with a very confident forecast of a 20-knot westerly wind. In fact, it proved to be easterly at 60 knots for more than half the way across. A figure of that sort is submerged in an average for the area; it doesn't appear at all. While, therefore, I am sure it is useful to know what the average is, what one really wants to know is 'What is the unaverage?' and 'When is it going to happen?' because that is what is going to kill you, not the average.

These are profoundly true words that indicate the practical navigator's viewpoint.

There is no doubt that, nowadays, it is essential to use statistical theories in the approach to navigational problems, but their practical application translated into a similarly practical language should not be lost sight of. As an example, we can point out how useful such theories may be in the determination of a criterion of rejection of an astro fix. Assuming that an astro position line has a standard error of $7.5 \mathrm{n} . \mathrm{m}$., we can infer that, in 95 per cent of the cases, the radius of the circumference inscribed in the position triangle is less than $10 \mathrm{n} . \mathrm{m}$. and thence establish a rule recommending that a fix should be suspected whenever the radius be greater than Io n.m. Another practical rule we have been using for a long time is the one suggested by Mr. Parker in his comments on Commander Sharpey-Schafer's notes on 'The Reliability of Sights at Sea' (this Journal, 8, 175). When we have a pair of position lines from the same celestial body, we reject the pair, after a check of the calculations and the plotting, any time they are apart by more than two standard deviations. If we accept the figure $7.5 \mathrm{n} . \mathrm{m}$. already mentioned, that will happen when the lines are apart by more than 15 n.m.

The paper presented by Mr. Durst opens new horizons to the study of the problem dealing with the accuracy of the D.R. position. Practical conclusions are to be drawn based on this and other studies that it will be necessary to make. We hope Air Chief Marshal the Hon. Sir Ralph Cochrane's words will not be forgotten.

7. ACKNOWLedgment. We have asked a number of practical navigators and meteorologists to criticize these notes. We are grateful for their comments and advice. We have used some figures and drills used in our Airline; however, the views set out in this paper are the author's own, not necessarily the Company's.

\section{Mr. C. S. Durst comments :}

It is exceedingly interesting to see in Captain Maya's notes the practical application of the knowledge of D.R. errors over Africa. In the first place it is 
very welcome to see the emphasis which he places on the difference between the use of expected errors when the penalty is only that of delay and when the question of safety is involved. The key must lie in the figures of the table below giving the likelihood of an actual error exceeding various multiples of the standard error, provided always that the errors follow the Gaussian law.

TABle I. LIKELIHOOD OF AN ACTUAL ERROR EXCEEDING IN MAgNitude Various MULTIPLES OF THE STANDARD ERROR, $S$ IN THE CASE OF SCALAR DISTRIBUTIONS, $V$ IN THE CASE OF TWO-DIMENSIONAL (VECTOR) DISTRIBUTIONS

\begin{tabular}{|c|c|c|c|c|c|c|c|c|}
\hline \multirow[b]{2}{*}{$\boldsymbol{x}$} & \multicolumn{8}{|c|}{ Chance of occurrence, one in $x$} \\
\hline & 2 & 4 & IO & 100 & 1000 & 10,000 & 100,000 & $1,000,000$ \\
\hline (S) Scalar distributions & 0.67 & $1 \cdot 15$ & $1 \cdot 65$ & $2 \cdot 6$ & $3 \cdot 3$ & 4 & $4 \frac{1}{2}$ & 5 \\
\hline (V) Vector distributions & 0.83 & $I \cdot 18$ & $1 \cdot 52$ & $2 \cdot 1$ & $2 \cdot 6$ & 3 & $3 \frac{1}{2}$ & $3 \frac{3}{4}$ \\
\hline
\end{tabular}

Thus there is about one chance in ten thousand that the error will be more than four times a scalar standard error or one chance in ten thousand that it will be more than three times a vector standard error, but there is always the provision that errors follow the Gaussian law and that no faults have occurred. Even one chance in ten thousand is appreciable when safety is at stake.

Captain Maya gives a most instructive list of the places on the African routes where errors are likely to be large and where they are likely to be small. In my paper ${ }^{1}$ I drew a conclusion that (given equal facilities) a forecast is more likely to be in error in those regions of the world and at those heights where the

Table II. Standard vector deviations on african Routes LISBON-DAKAR-LUANDA-LOURENÇO MARQUES

\begin{tabular}{|c|c|c|c|c|c|c|c|c|}
\hline Route & Jan. & \multicolumn{2}{|c|}{$500 \mathrm{mb}$} & Oct. & Jan. & \multicolumn{2}{|c|}{$700 \mathrm{mb}$} & Oct. \\
\hline Lisbon-C. Juby & 31 & 27 & 20 & 27 & 24 & 21 & 16 & 20 \\
\hline C. Juby-C. Blanco & 27 & 24. & 19 & 22 & I 8 & 19 & 16 & 17 \\
\hline C. Blanco-Dakar & 22 & 21 & I 8 & 20 & 15 & 15 & 15 & 16 \\
\hline Dakar-C. Palmas & 18 & I 8 & 17 & 17 & I 2 & 13 & I 3 & I 2 \\
\hline C. Palmas-C. Lopez & 14 & 15 & 16 & 16 & 10 & I 2 & 12 & I I \\
\hline C. Lopez-Luanda & 12 & 15 & 15 & 16 & 10 & I 2 & 13 & 13 \\
\hline $\begin{array}{l}\text { Luanda-Livingstone } \\
\text { Livingstone-Lourenço }\end{array}$ & 14 & 17 & 16 & I 7 & 10 & I I & 12 & I 3 \\
\hline Marques & 17 & 20 & 19 & I 9 & 12 & 14 & 15 & 13 \\
\hline \multicolumn{9}{|l|}{ Lisbon-Lagos } \\
\hline Lisbon-2 $5^{\circ} \mathrm{N} .0^{\circ} \mathrm{W}$ & 28 & 26 & 20 & 26 & 2 I & 20 & 16 & I 8 \\
\hline $25^{\circ} \mathrm{N} . \circ^{\circ} \mathrm{W}-\mathrm{Niamey}$ & 20 & 20 & 18 & 19 & 14 & 14 & 15 & I 5 \\
\hline Niamey-Lagos & 16 & 17 & 17 & I 7 & I I & I I & 13 & 12 \\
\hline
\end{tabular}


standard vector deviation of wind is larger than where it is small. Accordingly I have set out in the table below the values of the standard vector deviation of wind for some places on the routes Captain Maya mentions.

Of the regions mentioned by Captain Maya as being bad the first (south-east of Agadir) falls in a position where the standard vector deviation in winter amounts to over $30 \mathrm{kt}$. at $500 \mathrm{mb}$. and $24 \mathrm{kt}$. at $700 \mathrm{mb}$. Captain Maya says that errors of $60 \mathrm{n} . \mathrm{m}$. in an hour's flight are not uncommon. The second region (south of Cujda) falls in a position where the standard vector deviation is almost as great and there Captain Maya says that off course deviations occur of 40 or $50 \mathrm{n} . \mathrm{m}$. in an hour. The third region (between Livingstone and Lourenço Marques) has a standard vector deviation of about $19 \mathrm{kt}$. at 500 and on that route errors of $40 \mathrm{kt}$. occur.

In all three regions the errors mentioned are about twice the standard vector deviation. If no forecast were used and the flight plan were made on the normal winds of the season, such errors would be expected once in every 50 or 100 flights as can be seen from Table I. On the other hand, the two regions which Captain Maya quotes as being generally good, i.e. between S. Tomé and Luanda and between Dakar and Accra are those where the standard vector deviations are comparatively small and errors of 20 or $30 \mathrm{kt}$. would not be expected to occur often.

In regard to the form of the figure of error, there is some evidence 2 that in extra tropical latitudes the wind variation is nearly represented by a circle and it is probable that the wind forecasting errors are also represented by a circle. Near the equator it is now suspected that the wind variation is greater in the east-west direction than in the north-south. However, I have not come across any evidence so far that the distribution of errors along (or across) a track is so skew that the departures of wind from average are much more likely to be great in any one direction than in the opposite direction. In this, of course, allowance has to be made for the average wind and for this purpose the Meteorological Office, London, has prepared charts of the normal winds which were published in Geophysical Memoir $85^{2}$ and have now been revised and manifolded. 3

\section{REFEREN CES}

1 Durst, C. S. The accuracy of dead reckoning in the air. This Journal, 8, 91 .

2 Upper winds over the world. Geophysical Memoir 85.

3 Charts of average vector winds and standard vector deviation. Available in the Meteorological Office, price 28 s, a set.

\section{Mr. J. B. Parker comments:}

Mr. Durst has commented on the meteorological aspects of Captain Maya's interesting note. Captain Maya's timely warning of the dangers of uncritical application of statistical techniques, coupled with his sympathy with the ideas of using probabilistic methods in navigational practice, raise once again the question of how far it is legitimate to go in applying statistical theories to navigational practice.

It is convenient to distinguish first the case where the application of statistics is for the purpose of weighting a piece of information by means of an uncertainty zone, and then comparing it with a similar piece of information with 
a different weight. In this class falls the determination of the M.P.P., the finding of a 'most probable' wind velocity, and the determination of a fix from three or more position lines. In general, there is nothing objectionable in using statistical techniques in problems like this, provided the weights are roughly known, though of course when one weight is large and the other weight is small (e.g. accurate fix $v$ poor D.R.) the application of the technique, though correct, will give a solution so close to the more accurate piece of information that it is not worth while doing it in practice. For problems of this type it is quite immaterial whether we use the $5^{\circ}$ per cent, 95 per cent, or any other error; there may indeed be practical advantages in using smaller dimensions but the final outcome will be the same, just as if a sum were solved using yards as the units instead of feet.

The second type of problem is where safety is concerned. Here we come up against new problems. First there is the underlying assumption behind the methods, that all errors follow a known law. This is referred to by Mr. Durst. Evidently for the first type of problem, the existence of a fault, that is, a nonGaussian error, is not a serious matter; it can in general be detected by testing the consistency of the two pieces of information. In problems of safety, however, it is vital: what is the point, for example, in guaranteeing a one in a million chance of aircraft collision, providing all navigational errors are Gaussian, when the incidence of large non-Gaussian errors (due to blunder or equipment failure) is perhaps once per every thousand occasions?

The second objection is the economic one. To achieve higher degrees of safety, more and more has to be paid in airspace. Some of the penalties of guaranteeing safe passage across the Atlantic by controlling aircraft have already been referred to (this Journal, 9, 321 ). When we remember that such guarantees are only likely to be valid provided all errors are Gaussian it is a matter of some doubt whether statistical criteria should be used at all in putting forward rules where the safety of aircraft or ships is concerned.

Considering this problem of aircraft separation we see from Mr. Durst's table that, for a collision risk of one in a million, the two tracks should be separated by ${ }_{5} S$, where $S$ is the combined scalar navigational error of two aircraft on two adjacent tracks, which may be of the order of 10 to 20 nautical miles. Such a wastage in airspace is fantastic when we remember that the separation takes no account of large blunders, the very factors that are mainly responsible for accidents. It is clear that in applications such as this an uncritical appeal to standard deviations and one in a million chances is as dangerous as it is uneconomical. In the search for an alternative approach, statistics can be a valuable guide, but it must be used with great caution and above all common sense.

How might one proceed in making an $a b$ initio study into such problems? A first stage is surely to calculate the collision risk (for a given assumed traffic density) in the absence of all control. In this way we could find for a given risk the maximum traffic density at any one time that could be tolerated in the absence of all controls altogether. If this maximum is in practice only exceeded at exceptional periods, it might be more economic to take the chance rather than to initiate a complicated and expensive-and never quite infallible-control system. If on the other hand the risk is too great, we should first decide how much to reduce it (evidently the risk must be reduced by an order of magnitude if the administrative costs of control are to justify themselves) and then start 
planning in the light of our estimates not only of s.d.'s of navigational error but, more important, of blunder rates.

Returning to Mr. Willis's article $(9,3$ ro), it might be remarked that a system of controlling aircraft which leaves unimpaired a company's strategy of flying optimum path tracks has some attractions. A depression in mid-Atlantic will automatically provide some measure of traffic control, since westerly flying aircraft will choose a northerly, and easterly flying aircraft, a southerly route. May we hope that, in the problem of controlling aircraft across great regions of high traffic density, a good compromise may be reached between the theoreticians with their insistence of very small collision risks and the practical men with their needs not only of safety, but also of economy and simplicity?

\section{Aircraft Performance Standards}

$$
\text { from Captain H. L. Lee }
$$

IN his Presidential Address, Captain A. M. A. Majendie emphasizes the value of the Institute in preserving the essential link between theory and practice. Particularly in aviation there is a risk that the ingenuity of the designer will lose value unless it is directly associated with the practical work of the operator. As airborne equipment becomes more complex, the operator cannot hope to grasp more than the fundamentals of much of the theory behind it, and his criticisms must perforce be tentative and somewhat uncertain.

This writer has found considerable concern among other airline route pilots besides himself, about some aspects of aircraft flight performance. The subject was admirably outlined recently by $R$. E. Gillman.* But the present writer suggests that those responsible for the legislation, and those who carried out the research which preceded it, at some stages lost contact with the practical.

As an illustration the reader is asked to consider a case which frequently arises in connection with the Weight Altitude Temperature restrictions. A pilot is at a tropical airfield which is perhaps little more than a strip cut from the undulating bush; it is afternoon, and the temperature is so high, shall we say $35^{\circ} \mathrm{C}$., that he cannot take off. If he did so, and an engine failed, the aircraft would not be able to maintain that 1.9 per cent gradient of climb which the legislation requires. The pilot therefore waits until early evening when, the Sun having set, the temperature falls to the tabulated figure of perhaps $31^{\circ} \mathrm{C}$. The pilot may now proceed to take-off knowing that he is complying with the legislation.

There appear to be two flaws in this procedure. First, many pilots would consider that in the event of an engine failure on take-off, followed by the critical and very shallow climb such as is envisaged, the fact that it is dark will be a far more serious handicap than would be a slightly lower performance. When take-off conditions are not critical, darkness may indeed make little difference. It is precisely when conditions are marginal, especially when there are no ground reference lights, that only exceptional airmanship can obtain from

* Gillman, R. E. (1956). Operational performance standards for civil aircraft. This Journol, 9, 436 . 